\title{
INICIAÇÃO À DOCÊNCIA E ENSINO DE HISTÓRIA - DESAFIOS NA CONTEMPORANEIDADE
}

Fábio André HAHN ${ }^{1}$

Adaiane GIOVANNI ${ }^{2}$

RESUMO: O artigo examina, a partir das experiências desenvolvidas no PIBID, como o recurso tecnológico, mediado pelo professor, pode ser uma alternativa no processo de ensino-aprendizagem. A pesquisa foi desenvolvida com alunos dos $9^{\circ} \mathrm{S}$ anos do Ensino Fundamental de dois colégios públicos do Paraná a partir da observação in loco, da aplicação de questionário e da metodologia WebQuest. Verificou-se, quanto ao perfil dos estudantes e à influência das novas tecnologias, que o investimento na formação inicial e continuada do professor se apresenta como imprescindível para uma real mudança no atual contexto educacional.

PALAVRAS-CHAVE: PIBID. WebQuest. Ensino de história. Novas tecnologias. Formação de professores.

\section{Introdução}

A proposta deste artigo, como apontado no título, é atual, mas difícil de ser abordada. Apontamos duas razões para essa dificuldade. A primeira refere-se ao fato de que a iniciação à docência não é tema novo, e apresenta-se cada vez mais atual no cenário acadêmico, demonstrando os desafios que temos que enfrentar.

$\mathrm{Na}$ última década, inúmeras iniciativas foram desenvolvidas pelos governos federal e estadual na criação de programas destinados à formação de professores, uma forma de amenizar aspectos da fragilidade do ensino na Educação Básica, apesar de serem iniciativas bastante tardias. Dentre elas podemos destacar: (i) o Programa de Bolsas de Iniciação à Docência (PIBID), com atenção especial para os estudantes de graduação durante sua vivência acadêmica e sobre o qual trataremos com maior atenção; (ii) o Programa de Desenvolvimento Educacional (PDE), voltado para a

${ }^{1}$ Coordenador do subprojeto de História. PIBID - Programa Institucional de Bolsa de Iniciação à Docência. Docente do Programa de Mestrado Interdisciplinar em Sociedade e Desenvolvimento. UNESPAR - Universidade Estadual do Paraná. Campo Mourão - PR - Brasil. 87302-060 fabioandreh@gmail.com.

2 Mestranda do Programa Interdisciplinar em Sociedade e Desenvolvimento. Ex-bolsista. PIBID Programa Institucional de Bolsa de Iniciação à Docência - História. UNESPAR - Universidade Estadual do Paraná. Campo Mourão - PR - Brasil. 87302-060 - adaiane.ri@ gmail.com. 
qualificação dos professores em exercício da Educação Básica do estado do Paraná; e, mais recentemente, (iii) a criação do Pacto Nacional pelo Fortalecimento do Ensino Médio, que visa contribuir com a formação dos professores que atuam na etapa final da Educação Básica. Tudo parece apontar que há, efetivamente, maior atenção do poder público com relação à formação de professores, ao mesmo tempo em que, por isso mesmo, ficam reveladas as fragilidades que acompanham há muito tempo a atuação das escolas, especialmente a pouca atenção dada à formação de professores da Educação Básica ao longo de décadas.

O Programa de Bolsas de Iniciação à Docência (PIBID), assim como em numerosas instituições de ensino superior (IES), é desenvolvido também, desde 2012, no Campus de Campo Mourão da Unespar. Diferentemente dos cursos de História das demais IES, tivemos o privilégio de contar com a implantação do programa já no segundo ano de existência do curso, fato que impactará positivamente na formação dos professores de História na região de abrangência. A proposta do subprojeto, em sua primeira fase, intitulado "Iniciação à Docência: a formação do professor de História", visava investigar características dos estudantes, a realidade das escolas e desenvolver e aplicar atividades com novas metodologias para o ensino de história e em diferentes espaços de formação. As atividades desenvolvidas tiveram como foco prioritário alunos dos $9^{\circ} \mathrm{s}$ anos do Ensino Fundamental, o que constitui uma iniciativa importante para um contexto em que as fragilidades da Educação Básica cada vez ficam mais evidentes no cotidiano de trabalho.

A segunda razão refere-se à constatação de que não há certezas nesse âmbito de discussões. Para discutir o ensino de História podemos, de forma exploratória, apontar algumas questões que podem ser relevantes para o momento histórico em que vivemos, mais especificamente três: primeiro, as novas tecnologias que têm marcado profundamente a mudança das relações sociais, o acesso à informação e apontado novos caminhos que podem e precisam repercutir no ensino, porém de forma qualificada, são uma realidade já presente; depois, o perfil dos estudantes, que mudou rapidamente nesta última década, em parte pelas transformações tecnológicas, mas também como resultado das alterações culturais, sociais e econômicas, que, de modo geral, têm impactado nossa sociedade; por fim, a verificação da falta de interesse e da dificuldade da aprendizagem

\footnotetext{
${ }^{3}$ O subprojeto de História do PIBID foi desenvolvido durante os anos de 2012 e 2014 e contou com a participação de 15 acadêmicos de graduação, 2 professores supervisores das escolas participantes e 1 professor coordenador da Universidade.
} 
dos alunos pelo estudo da História nas escolas, o que não é mais novidade e nem exclusividade desta área.

Todos esses elementos nos ajudam a pensar na escola e no ensino de História, que enfrenta esses desafios ainda timidamente, mas que precisam ser enfrentados por nós e pelos futuros professores com novas práticas de ensino nos mais diversos espaços de formação.

As perspectivas para a aprendizagem da História têm demonstrado importantes questões. A principal parece voltada ao fato de que aprender história deve ser entendido como condição para a formação cidadã, partindo da realidade social dos alunos e dos professores, de modo que se sintam como sujeitos da constituição da história.

Os historiadores que atualmente investigam esse contexto abordado (BITTENCOURT, 2005; CAIMI, 2009) ressaltam a importância do uso das fontes históricas em sala de aula. Trabalhadas adequadamente, essas fontes poderiam favorecer o desenvolvimento do pensamento histórico e o entendimento do processo de produção do conhecimento. Dessa forma se poderia romper o verbalismo, a reprodução e a memorização nas aulas de História, possibilitando a formação de um estudante ativo e com condições de aprender a formular hipóteses e até de aprender a classificar, a analisar e a avaliar a credibilidade das fontes.

Com essas ponderações, entendemos que é necessário nos aprofundar no estudo da História, assim como nos aproximar das novas tecnologias e da realidade dos estudantes. As novas metodologias a partir do uso da tecnologia para o ensino de História podem ajudar, desde que contextualizadas com a realidade escolar, sendo necessária a conscientização de que a tecnologia não traz apenas benefícios, pois, quando não mediada adequadamente, surte efeito oposto, gerando consumo de informações instantâneas, sem gerar aprendizagem.

Diante desse contexto, a proposta deste artigo é apresentar como o recurso tecnológico, mediado pelo professor, pode ser uma alternativa no processo de ensinoaprendizagem. Leva-se em consideração que, para que o professor possa ser um mediador qualificado, é preciso urgência de investimentos na sua formação inicial e continuada, o que permitirá maior legitimidade tanto na condução adequada da utilização dos recursos tecnológicos, quanto na possibilidade de formação dos alunos da Educação Básica.

Desenvolveremos nosso argumento em três momentos. Primeiro reconstruiremos aspectos do contexto dos estudantes de duas escolas públicas (1). 
Depois, buscaremos demonstrar brevemente o desenvolvimento e aplicação da metodologia WebQuest no ensino de História (2). Por último, nas considerações finais (3), apontaremos as convergências e diferenças entre os colégios investigados.

\section{Elementos contextuais}

Para pensar uma mudança no ensino de História que ainda mantém aspectos de um formato tradicional, ancorado no verbalismo, na reprodução e na memorização como apontado anteriormente -, é preciso conhecer melhor o público a ser estudado. As duas escolas públicas contempladas pelo subprojeto apresentaram estudantes com características tanto semelhantes, quanto diferentes. Localizadas em espaços diferentes, uma escola no centro e outra na região periférica da cidade, apresentaram quantitativos de alunos completamente diferentes, sendo que a da área central é composta por quatro turmas com 95 alunos do nono ano, e a periférica com três turmas de 57 alunos. Estudar os estudantes nessas duas realidades do mesmo município tem por objetivo questionar os estereótipos que permeiam nosso olhar sobre os jovens. A intenção é chamar a atenção para as especificidades da realidade desse público, que adentra a escola trazendo experiências, vivências e saberes que, por muito tempo, foram desconsiderados no processo de ensino-aprendizagem.

As duas escolas foram frequentadas semanalmente pelos estudantes vinculados ao projeto. A vivência com os estudantes permitiu compreender um pouco da realidade e dos dilemas vivenciados por eles. Optamos, no entanto, em determinado momento, por aplicar um questionário de modo que fosse possível compreender algumas especificidades da realidade dos alunos em cada uma das escolas.

Selecionamos apenas algumas das questões aplicadas para este estudo. Levando em consideração as demandas apresentadas pelos estudantes na contemporaneidade, dividimos as questões em dois blocos. No primeiro bloco selecionamos três questões referentes à relação do aluno com a escola.

A primeira pergunta do primeiro bloco foi sobre se o aluno sempre estudou em escola pública: 


\section{Figura 1 - Gráfico referente à vinculação com a escola pública}
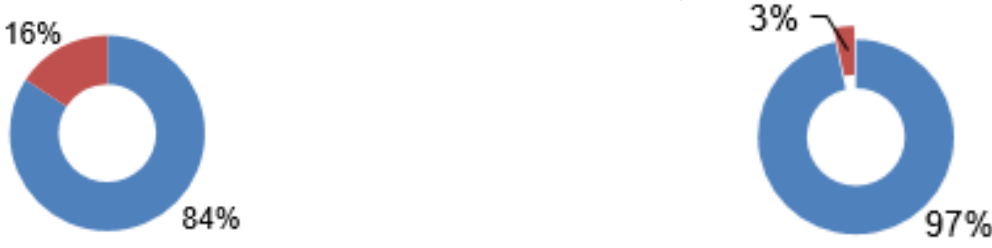

- SIM $\square$ NÃO

\section{Colégio Central}

\section{Colégio periférico}

Fonte: Elaboração própria com base nos dados coletados pela pesquisa.

Os dados apresentados deixam claro o papel da escola pública para os estudantes. No colégio periférico há uma quase unanimidade do percurso histórico de estudos realizado em escola pública, com variação referente ao colégio situado na região central.

Quanto à segunda pergunta do primeiro bloco, os alunos foram questionados se já ficaram algum ano sem estudar ou se repetiram de série, eles responderam que:

Figura 2 - Gráfico referente à desistência ou repetição de série
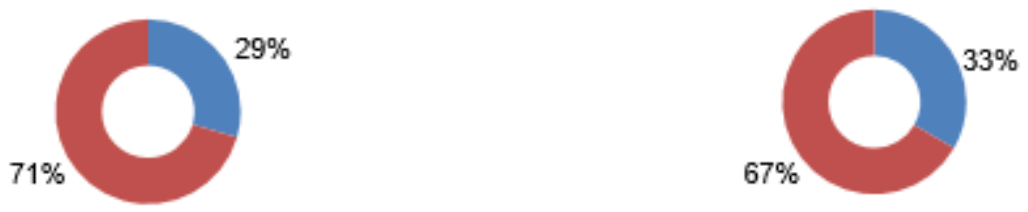

$\because \operatorname{SIM} \backsim N A \tilde{O}$

\section{Colégio Central}

Colégio periférico

Fonte: Elaboração própria com base nos dados coletados pela pesquisa.

Nos dois colégios, com pequena variação entre eles, observa-se um resultado muito semelhante e preocupante. A média de aproximadamente $30 \%$ de desistência ou repetição de série é significativamente alta.

A terceira pergunta do primeiro bloco questiona sobre se alguma das pessoas da sua família já cursou ensino superior ou se está cursando. Responderam:

Figura 3 - Gráfico referente a algum membro da família ter cursado Ensino Superior

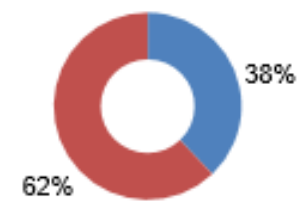

$\because$ SIM $\amalg N A \tilde{O}$

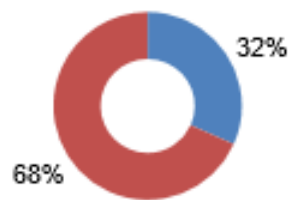




\section{Colégio Central}

Colégio periférico

Fonte: Elaboração própria com base nos dados coletados pela pesquisa.

$\mathrm{O}$ cruzamento das respostas à segunda e à terceira pergunta demonstra, em um primeiro momento, que não há necessariamente um estímulo ao estudo dos estudantes pelo fato de um dos membros da família já ter cursado ou estar cursando algum curso de nível superior. Os dados são altos se pensarmos que, em média, 35\% dos alunos têm alguém de sua família que já fez ou está fazendo curso superior. Então, ao comparar a taxa de evasão ou de repetência, chegamos quase nos mesmos índices. Esses fatos, em um primeiro momento, revelam aspectos do contexto dos estudantes. O que se pode entender é que parte significativa de alunos é oriunda de escola pública e nela continuam estudando. Além disso, apresentam altas taxas de repetência e de desistência, apesar de terem algum estímulo dentro de casa.

Agora, em um segundo bloco de questões, relacionamos conhecimentos de informática e acesso à internet. Quando perguntados se têm acesso à internet, os alunos responderam que:

\section{Figura 4 - Gráfico referente ao acesso à internet}

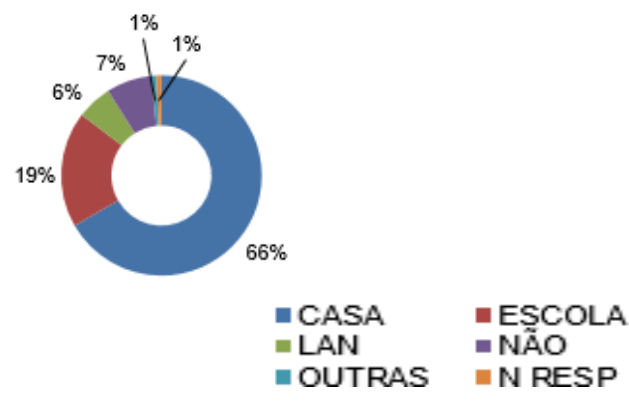

Colégio Central

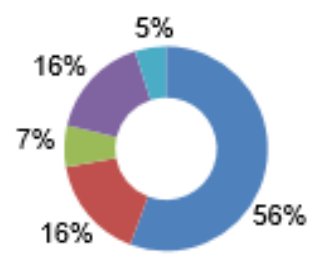

Colégio periférico

Fonte: Elaboração própria com base nos dados coletados pela pesquisa.

Os dados revelam que a maior parte dos estudantes tem acesso à internet, no entanto um grupo significativo de alunos está excluído desse mundo da comunicação, sendo que o colégio central apresentou uma taxa de 7\% dos que não têm acesso, enquanto no da região periférica eles são $16 \%$.

Já quando questionados se têm conhecimento em informática, os alunos responderam que: 


\section{Figura 5 - Gráfico referente ao conhecimento de informática}

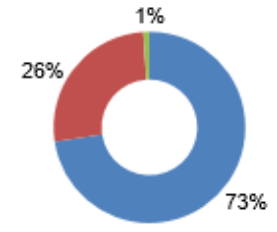

Colégio Central

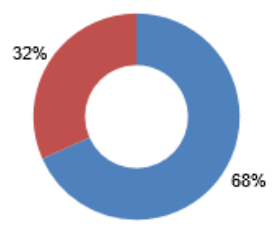

Colégio periférico

Fonte: Elaboração própria com base nos dados coletados pela pesquisa.

Uma média de quase $30 \%$ dos alunos declararam que não têm conhecimento em informática. Há, portanto, uma realidade bastante controversa ao pensarmos que não basta ter computador, pois é preciso saber lidar com as ferramentas. Nessa mesma direção, identificamos que o laboratório de informática nas escolas ainda tem uso e acesso muito restrito. Não é nenhuma novidade nos deparamos com problemas nos computadores no laboratório de informática escolar. Ainda pior em alguns casos é o acesso à internet, acesso que geralmente é precário, com pouca funcionalidade em virtude da lentidão e da instabilidade.

Quando os alunos são questionados se têm acesso/aula no laboratório de informática na escola, responderam que:

Figura 6 - Gráfico referente ao acesso ao laboratório de informática na escola

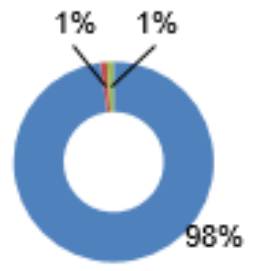

Colégio Central

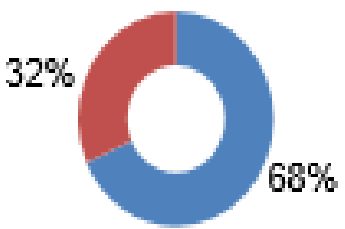

Colégio periférico

Fonte: Elaboração própria com base nos dados coletados pela pesquisa.

Como se pode perceber, a informação variou muito de colégio para colégio. Enquanto o da região central apresenta taxa altíssima de acesso, o da região periférica da cidade aponta que mais de $30 \%$ dos alunos não têm acesso a esse espaço para o desenvolvimento de atividades e pesquisa. 
A partir dessas questões apresentadas e da verificação in loco, optamos por apresentar uma alternativa ao ensino de História a partir do uso da tecnologia educacional.

\section{Metodologia WebQuest no ensino de História}

O laboratório de informática na escola é espaço de formação ainda muito mal aproveitado para os procedimentos de ensino-aprendizagem, pois que, em geral, professores e alunos o enxergam com certo exotismo e curiosidade. A "navegação" pela internet é uma possibilidade atraente, no entanto é preciso pensar como esse espaço pode ser melhor utilizado para o ensino, neste caso, para o ensino de História. Como lidar com as ferramentas desse mundo virtual? Esse é o desafio tanto para professores quanto para alunos.

Se existe a necessidade de criar condições de aprendizagem pelo uso dos recursos das novas tecnologias, é preciso também que as escolas tenham a tecnologia disponível para o planejamento dessas atividades, assim como programas (softwares) e sites educativos a serem explorados, e, acima de tudo, que os professores sejam qualificados para conseguirem utilizar adequadamente as inúmeras ferramentas possíveis para o processo de ensino-aprendizagem. O fato de os professores, em geral, não estarem qualificados nessa utilização, essa é uma realidade que não pode ser ignorada. Como destacou Tavares (2012), os professores precisam ser instruídos no uso do computador, superando o medo e a desconfiança em relação ao uso da tecnologia.

O professor, como destacou Valente $(2002,2005)$, deve conhecer o que cada uma dessas facilidades tecnológicas tem a oferecer e como pode ser explorada em diferentes situações educacionais. Como ele mesmo destacou, é preciso que o professor tenha condições de aliar conhecimentos técnicos e pedagógicos, de modo que possa orientar e desafiar os alunos para que a atividade contribua para a geração de novos conhecimentos. Ou seja, as representações mentais dos alunos precisam ser confrontadas entre si para que ocorra a aprendizagem, impondo um freio de emergência que desacelere o processo aparentemente inócuo de distração, para que possam pensar e discutir sobre o que aprenderam (ZUIN; ZUIN, 2011).

Uma alternativa proposta no projeto PIBID de História foi desenvolver atividades com a metodologia WebQuest. Essa metodologia é pouco conhecida no 
ensino de História nas escolas brasileiras, mas já vem sendo utilizada há alguns anos em todos os continentes, com destaque especial para países como Espanha e Portugal, onde tem mostrado interessantes resultados.

A metodologia em si e o conceito foram criados em 1995 por Bernie Dodge e Tom March, tendo por proposta o desenvolvimento de uma atividade investigativa com o uso da internet. A proposta WebQuest é elaborada e orientada pelo professor com questões e tarefas a serem investigadas por grupos de alunos. Trata-se, portanto, de uma atividade de aprendizagem colaborativa, podendo fazer uso na pesquisa de fontes principalmente em páginas da web, mas também pode recorrer a outros recursos, como livros, vídeos e imagens.

Desenvolvemos, de forma simples e experimental, uma WebQuest aos alunos dos $9^{\circ}$ s anos, tanto no colégio central, quanto no periférico. A opção foi por desenvolver uma WebQuest curta (tendo em vista o pouco tempo que teríamos para sua aplicação), objetivando fazer melhor uso do tempo do aluno. Assim, portanto, para que se possa atingir maior eficiência e clareza na resolução dos problemas, a WebQuest deve sempre ser orientada e supervisionada pelo professor, evitando o que Dodge (1995) chamou de "surfagem" pela rede. ${ }^{4}$

Ocorreu-nos, no entanto, que, ao iniciarmos a verificação da viabilidade da aplicação das WebQuests nos laboratórios de informática dos colégios, encontramos problemas em um deles. O colégio localizado na região periférica da cidade apresentou conexão com a internet muito instável e lenta, além de mau funcionamento de alguns computadores. Essa situação inviabilizou naquele colégio a aplicação efetiva da metodologia. Mesmo assim, seguimos construindo o mesmo processo nos dois colégios, com algumas diferenças que apontaremos mais à frente.

O primeiro passo foi aprofundar a leitura sobre a metodologia de modo que pudéssemos desenvolver o material pertinente ao conteúdo trabalhado em sala de aula e aplicar a WebQuest com sucesso. Com base em Dodge (1995), Bottentuit Junior e Coutinho (2012), desenvolvemos as WebQuests em algumas etapas constitutivas, como: (i) introdução ao tema, com objetivo de preparar a proposta e fornecer informações gerais; (ii) a tarefa com linguagem simples, para estimular o aluno a desenvolvê-la; (iii) o processo no qual o aluno deverá se orientar para a realização da tarefa; (iv) os

${ }^{4}$ Recentemente, por inspiração nas atividades desenvolvidas no PIBID, realizamos a ampliação da proposta em outro projeto e criamos o site intitulado "Janela para a História" (HAHN, 2013). Pretende-se que o site seja uma alternativa e recurso ao ensino de História, no qual disponibilizamos casos a serem aplicados e resolvidos. 
recursos caracterizados como pistas disponíveis na web para a produção do conhecimento; (v) a avaliação, que fornece ao aluno os indicadores qualitativos e quantitativos referentes à atividade proposta; e (vi) a conclusão, que propõe um desfecho da proposta sobre o que aprenderam, mas que também aponta para a continuidade da investigação.

No colégio central, trabalhamos com vários temas diferentes, acompanhando o conteúdo abordado na disciplina e nas turmas selecionadas para a aplicação. Para a construção da WebQuest existem recursos disponíveis na internet que não demandam de experiência de programação por parte do autor para construir a interface, pois basta acessar um portal de WebQuest que melhor atenda às necessidades da atividade que será proposta, solicitar uma senha e definir um layout para produzir a WebQuest. Uma possibilidade que vem sendo utilizada com sucesso é o Google Sites, que possibilita a montagem da interface de acordo com as preferências de quem a constrói, sem modelos predefinidos.

Passada a etapa de produção das informações e da construção da interface, iniciamos a aplicação da metodologia. Após a exposição do funcionamento da ferramenta no laboratório de informática, os alunos foram divididos em duplas, de modo que fosse estimulado o trabalho colaborativo de investigação entre eles.

Foram desenvolvidas várias WebQuests pertinentes aos temas do currículo dos alunos do $9^{\circ}$ ano. Os resultados foram positivos. Nas observações realizadas in loco constatou-se que os alunos se mostraram interessados em desenvolver as tarefas propostas. Ao serem perguntados sobre o que acharam dessa proposta de trabalho, as respostas principais foram congregadas em duas direções: na primeira foi ressaltada a importância de desenvolver atividades fora da sala de aula, portanto em outros espaços de formação; na segunda, ressaltaram o fato de terem realizado a atividade coletivamente com o uso da internet e que conseguiram compreender o conteúdo pelas diferentes informações e diferentes fontes disponibilizadas, o que foi perceptível na fala dos alunos, mas também no resultados das tarefas realizadas.

Com isso, atingimos um duplo resultado: (i) por um lado a participação dos acadêmicos pibidianos no desenvolvimento e na aplicação de metodologia a partir dos novos recursos tecnológicos; (ii) por outro, a boa recepção por parte dos alunos nas escolas e seu aproveitamento positivo no processo de ensino-aprendizagem a partir das atividades desenvolvidas. O que fica explicitado é que a utilização de novos recursos da tecnologia educacional é uma alternativa importante e que precisa ser investigada e 
desenvolvida, pois, como ressaltam Briggs e Burke (2006, p.309), precisamos caminhar "[...] rumo a um espaço de ensino que não seja restritamente marcado por "paredes"”.

No colégio periférico, a proposta desenvolvida seguiu a mesma estrutura proposta para a WebQuest, no entanto teve que ser adaptada em virtude do funcionamento instável e lento da internet no laboratório de informática. O que foi evidenciado nos dados resultantes do questionário aplicado, em que os alunos foram perguntados sobre o acesso e aulas no laboratório de informática da escola, é que $32 \%$ deles (conforme suas respostas) não têm acesso a esse espaço tampouco têm aulas ali desenvolvidas, fato de que não ficou difícil de entender a causa.

A saída apresentada foi imprimir as diferentes etapas da WebQuest em papel, alterando os recursos que seriam pesquisados na web por pesquisa nos materiais disponíveis na biblioteca, tanto de fontes, como de mapas e de referências bibliográficas. Entretanto, apesar das adaptações e da sequência da proposta metodológica, a atividade desenvolvida deixou de ser originalmente uma WebQuest por não utilizar os recursos da web, mas segue os mesmos princípios. Conforme Bottentuit, Junior e Coutinho (2012, p.75),

[...] para ser uma verdadeira WebQuest, a atividade deveria incluir tarefas que solicitassem a transformação da informação pesquisada e recolhida num novo produto ou numa nova informação que refletisse a capacidade dos alunos criarem novos saberes.

Nesse quesito, a proposta desenvolvida desempenhou seu papel. Os resultados foram interessantes. Apesar de o acesso aos recursos ter transcorrido mais lentamente, o resultado da tarefa foi atingido, demonstrando o princípio principal da WebQuest, conforme apontado pelos autores acima: a transformação em uma nova informação, em um novo saber, em conhecimento.

O laboratório de informática na escola, entendido com um espaço de formação, precisa fazer parte efetiva das aulas de História, desde que planejadas e desenvolvidas com metodologia e ferramentas apropriadas, pois, como destacou Tavares (2012, p.301), “[...] é inegável que as transformações tecnológicas, aliadas à crescente produção de equipamentos e programas em atendimento às demandas de mercado, vêm fazendo uma significativa alteração de usos, costumes e práticas, especialmente entre os mais jovens". A História está presente na internet e com muita força. Inúmeros eventos na área de História digital ocorrem e estão disponíveis on-line, sem falar de redes 
sociais como Café História, que já possui mais de 54.000 participantes e que, atualmente, é a maior rede social de História da internet e que, ao longo de seis anos, já ultrapassou a marca de 20 milhões de acessos (FAGUNDES; HAHN, 2014), sem falar de inúmeras matérias em jornais e em revistas produzidas e disponibilizadas.

O interesse por História, bem como o seu consumo, é grande. ${ }^{5}$ Como destacou em entrevista Leal (apud (FAGUNDES; HAHN, 2014, p.17), criador da rede social Café História, “[...] talvez estejamos entrando em uma era de história aberta”. Temos conteúdo de História qualificado na rede, basta fazer a triagem do que é útil ou não, sendo esta triagem, portanto, um papel fundamental do professor. Com tudo isso apontado, a escola não pode mais ficar alheia a esse contexto de mudanças e de novas tecnologias, pois as práticas por parte dos estudantes são novas e precisam encontrar espaço na educação formal.

\section{Considerações finais}

Os colégios central e periférico apresentam diferenças bastante distintas e estão manifestadas nos dois níveis estudados neste breve estudo exploratório: no contexto dos estudantes e no laboratório de informática com o emprego da metodologia WebQuest. Não obstante, também há convergências entre os colégios observados.

O contexto dos estudantes, como marcado por algumas avaliações, revela que, predominantemente nos dois colégios, os alunos sempre estudaram em escola pública, apresentam taxas de desistência e de repetência próximos e o acesso ao ensino superior de pelo menos um membro da família não destoa significativamente entre os colégios. As variações entre os colégios, de modo geral, estão marcadas por questões socioeconômicas, dentre as quais a mais flagrante é a diferença de renda familiar (RIPPER; BRAGA; MORAES, 1993). O que chamou a atenção foi que, apesar de um número representativo dos alunos ter ao menos um membro da família que teve acesso ao ensino superior, as taxas de desistência e de repetência são altas.

O acesso ao Ensino Superior não é estímulo suficiente para que uma parcela dos alunos apresente melhor desempenho na escola. A média aproximada de $31 \%$ é bastante alta e necessita ser investigada com maior cuidado.

${ }^{5} \mathrm{Na}$ Universidade Estadual do Paraná (Unespar) temos, a partir do projeto de extensão coordenado pelo professor Bruno Flávio Lontra Fagundes, uma experiência bastante interessante. Bimestralmente os acadêmicos do curso de História produzem e publicam matérias de história na Revista Metrópole, que tem circulação impressa e on-line. O que demonstra o interesse cada vez maior do grande público pela história. 
No que diz respeito ao laboratório de informática e o emprego da metodologia WebQuest, investigamos, inicialmente, algumas questões, como o fato de os alunos terem acesso à internet. Quanto ao acesso na própria residência, no colégio central esse acesso alcançou $66 \%$ dos alunos e, no periférico, apenas 56\%. É índice bastante baixo, tendo em vista que é em casa que o uso ainda é mais frequente. Além disso, no colégio central $7 \%$ e no periférico $16 \%$ não têm nenhum acesso à internet, o que revela a exclusão de um número significativo de alunos desse campo de informação. $\mathrm{O}$ agravante maior está nos dados sobre conhecimentos de informática, quando $26 \%$ dos estudantes do colégio central e $32 \%$ do periférico responderem não terem esses conhecimentos básicos de informática. Ou seja, acionam materiais e realizam tarefas simples sem terem razoável conhecimento de informática.

Dadas essas semelhanças entre os estudantes dos dois colégios e voltando às disparidades, a maior entre elas ficou revelada quando questionados sobre o fato de terem aulas ou acesso ao laboratório de informática escolar. No colégio central apenas $1 \%$ informou que não tem, portanto é praticamente unânime a informação de que esse acesso existe. Por outro lado, $32 \%$ dos alunos do colégio periférico informaram não terem aulas nem acesso ao laboratório da escola. A diferença ficou evidente também na aplicação prática da pesquisa. Na tentativa de reverter isso, propusemos o trabalho com a metodologia WebQuest, ocasião em que se demonstrou claramente o porquê dessa distorção.

A atividade prática no colégio central foi bem sucedida, mas no colégio periférico ocorreram alguns inconvenientes que prejudicaram o trabalho com a metodologia, como lentidão e instabilidade da conexão com a internet; computadores com problemas de funcionamento; e ninguém habilitado para dar suporte nesse espaço de formação. Isso não impediu que a proposta fosse desenvolvida, pois, com alguns ajustes e algumas alterações, a proposta de estudo foi aplicada por meio de uso e pesquisa em livros e fotos. Esse improviso, no entanto, apresentou uma realidade bastante comum nas escolas públicas brasileiras, o que dificulta falar em uso das novas tecnologias na Educação Básica quando ainda vivenciamos dificuldades primárias. Nem por isso deixamos de apresentar uma alternativa eficiente de lidar com possibilidades metodológicas para o ensino de História através de um trabalho colaborativo e orientado pelo professor.

Por fim, a escola precisa se adequar às mudanças contextuais, mas, para que isso ocorra, é preciso de investimento mais sólido em pesquisas sobre a Educação Básica, 
assim como sobre as tecnologias educacionais, mas, acima de tudo, investimento na formação do professor (CAIMI, 2006; ZUIN; ZUIN, 2011; MIRANDA, 2008). Esse investimento é elemento fundamental para que tanto o uso das novas tecnologias, quanto o ensino em diferentes espaços de formação possam se efetivar de forma mais eficiente. Não é nenhum segredo que o governo investiu altas somas de recursos na criação de novas universidades desde os anos 1990, mas esses investimentos foram pouco direcionados à formação de professores, tanto formação de novos professores, quanto formação continuada para professores na ativa.

A Educação Básica pouco se beneficiou dos investimentos realizados por parte do Estado. O professor precisa estar em condições de refutar informações equivocadas, fazer interpretações qualificadas, estimular os alunos a pensar e analisar erros e acertos. Para que isso possa se tornar realidade, o investimento qualificado no professor é elemento fundamental para o avanço na educação.

Ao professor não basta ter conhecimento técnico sobre computadores, mas deve estar preparado para criar condições para a construção do conhecimento, perceber as perspectivas educacionais, as diferentes aplicações do computador para uma adequada prática pedagógica. E, como já apontou Valente (2002, 2005), a formação precisa ser pensada na forma de uma espiral crescente de aprendizagem, de modo que possa tratar tanto das questões técnicas, quanto das questões pedagógicas.

\section{INITIATION TO THE TEACHING PROFESSION AND THE TEACHING OF HISTORY-CONTEMPORARY CHALLENGES}

ABSTRACT: This paper examines, based on the experience obtained within PIBID, how teacher-mediated technological resources can become an relevant alternative in the teaching-learning process. This study was conducted with 9th grade pupils in two public Elementary Schools in Paraná State (Brazil) based on in loco observations, the adminsitration of a questionnaire and the use of the WebQuest methodology. Taking into consideration the profile of the pupils and the influence of new technologies, it was concluded that investiment in initial and continued teacher training is imperative so that real changes in the current educational context can occur.

KEYWORDS: PIBID. WebQuest. History teaching. New technologies. Teacher training.

\section{REFERÊNCIAS}


BITTENCOURT, C. Identidade nacional e ensino de história do Brasil. In: KARNAL, L. (Org.) História em sala de aula: conceitos, práticas e propostas. São Paulo: Contexto, 2005. p.185-204.

BOTTENTUIT JUNIOR, J. B.; COUTINHO, C. P. Recomendações de qualidade para o processo de avaliação de WebQuests. Ciências \& Cognição, Rio de Janeiro, v.17, n.1, p.73-82, 2012.

BRIGGS, A.; BURKE, P. Uma história social da mídia: de Gutenberg à internet. Rio de Janeiro: Zahar, 2006.

CAIMI, F. E. História escolar e memória coletiva: como se ensina? Como se aprende? In: MAGAlHÃES, M.; ROCHA, H.; GONTIJO, R. (Org.). A escrita da história escolar: memória e historiografia. Rio de Janeiro: Editora FGV, 2009. p.65-79.

Por que os alunos (não) aprendem História? Reflexões sobre ensino, aprendizagem e formação de professores de História. Tempo, Rio de Janeiro, v.11, n.21, p.17-32, 2006.

DODGE, B. WebQuests: a technique for internet - based learning. The Distance Educator, [S.1.], v.1, n.2, 1995.

FAGUNDES, B. F. L.; HAHN, F. A. História e realidades on-line: colocações sobre produção, difusão e ensino - Bruno Leal. Revista NUPEM [online], v.6, p.11-25, 2014.

HAHN, F. A. (Coord.). Janelas para a história. Campo Mourão: UNESPAR, 2013. Disponível em: <http://www.unespar.edu.br/janelaparaahistoria/>. Acesso em: 19 jun. 2015.

MIRANDA, S. R. Lugares de memória, espaços de formação: elos invisíveis na constituição do conhecimento histórico de professores. In: ZAMBONI, E.; FONSECA, S. G. (Org.) Espaços de formação do professor de história. Campinas: Papirus, 2008. p.261-280.

RIPPER, A. V.; BRAGA, A. J. P.; MORAES, R. A. O projeto EUREKA. In: VALENTE, J. A. Computadores e conhecimento: repensando a educação. 2.ed. Campinas: Ed. da UNICAMP, 1993. p.409-418.

TAVARES, C. C. S. História e Informática. In: CARDOSO, C. F.; VAINFAS, R. Novos domínios da história. Rio de Janeiro: Elsevier, 2012. p.301-317.

VALENTE, J. A. A espiral da aprendizagem e as tecnologias da informação e comunicação: repensando conceitos. In: JOLY, M. C. Tecnologia no ensino: implicações para a aprendizagem. São Paulo: Casa do Psicólogo Editora, 2002. p.15-37.

Pesquisa, comunicação e aprendizagem com o computador. O papel do computador no processo ensino-aprendizagem. In: ALMEIDA, M. E. B.; MORAN, J. M. (Org.). Integração das tecnologias na educação. Brasília: Ministério da Educação Secretaria de Educação a Distância, 2005. p.22-31.

ZUIN, V. G.; ZUIN, A. A. S. Professores, tecnologias digitais e a distração concentrada. Educar em Revista, Curitiba, n.42, p.213-228, out./dez. 2011. 